\title{
DIREITOS SOCIAIS E JUSTIÇA A EXPERIÊNCIA NORTE-AMERICANA
}

\author{
José Reinaldo de Lima Lopes \\ Professor Doutor do Departamento de Teoria Geral e Filosofia do Direito \\ da Faculdade de Direito da Universidade de São Paulo
}

Resumo:

Este trabalho pretende ser um estudo comparativo de como o Poder Judiciário norte-americano enfrentou questões distributivas, de políticas públicas e direitos sociais. Inicialmente referimo-me às análises das críticas feitas ao envolvimento do Judiciário em temas tradicionalmente reservados ao Legislativo ou ao Executivo. A seguir, analiso três casos exemplares em diferentes momentos da história neste século: os casos da reforma monetária de Roosevelt, a reforma dos hospitais psiquiátricos do Alabama e, finalmente, a política de imigração nos anos 90 . Termino comentando as diferenças mais notáveis com o Brasil.

\begin{abstract}
:
This paper is intended to make a comparative analysis of the ways in which the American Judicial branch has dealt with distributive matters, public policies and social rights. I begin with a reference to the critical analysis made on the involvemente of courts with issues traditionally left to the Legislative and Executive branches. I continue by studying three paradigmatic cases brought to court in this century: the monetary reforms of Roosevelt, the psychiatric hospitals of Alabama and the immigration policies of the 90 s. I end with a short note on the most noticeable differences with the Brazilian case.
\end{abstract}

Unitermos: justiça social; poder judiciário; direitos sociais.

* Este trabalho foi possivel graças ao apoio financeiro da Fapesp-Fundação de Amparo à Pesquisa do Estado de São Paulo, ao apoio institucional da Universidade de São Paulo e da Universidade da Califórnia, San Diego (Departamento de Ciência Politica). Pessoalmente, sou devedor de James Holston, professor da UCSD, pelo debate e pelas críticas. Na minha ausência da USP fui generosamente substituido por José Eduardo Faria, Francisco José Calheiros Ferreira e Antônio Maués. Devo muito ao diálogo com Elisa P Reis, da UFRJ, e à amizade de Gessé Marques Jr. 
1. Introdução: O que está em jogo.

Este trabalho é uma primeira tentativa de comparar a atuação do judiciário em matérias de políticas públicas. A comparação com os EUA é pertinente, porque nosso modelo de controle de constitucionalidade é inspirado no norte-americano e antecede de muitas décadas a experiência européia. Para qualquer comparativista os contrastes entre Brasil e EUA são, assim mesmo, enormes. O respeito dos juízes norte-americanos pela presunção de constitucionalidade das leis é maior do que o dos brasileiros. Assim também seu respeito pelos precedentes das Cortes superiores. O nosso sistema de carreira, sendo de matriz européia, contrasta com o regime dos norte-americanos. Tudo isto merece ser lembrado.

A Constituição norte-americana desempenha um papel único na discussão política e jurídica do país. Contrariando a tradição inglesa, na qual o direito é muito jurisprudencial, a constituição é um documento normativo, uma fonte de direito conscientemente elaborada. Por outro lado, a cultura jurídica continua operando dentro da visão de que o direito é também produzido por precedentes consistentes dos tribunais. A Suprema Corte é ponte entre estas duas versões de um sistema jurídico: é chamada a dizer o que é constitucional, e assim é em última análise criadora da constitutional law. Ao mesmo tempo, tem consciência de que não pode se desfazer de um precedente com facilidade: sua autoridade provém do fato de que o direito (lcw) não pode ser objeto de sua disposição absoluta e um mínimo de direito natural (racional, lockeano, etc.) está incorporado à cultura jurídica e é permanente a idéia de rule of law.

Os direitos sociais dos cidadãos norte-americanos nunca foram explicitamente integrados à Constituição. Isto não impediu que fossem incorporados por decisões da Suprema Corte. Esta, interpretando a XIV Emenda de forma ampla, garantiu um mínimo de constitucionalidade às políticas sociais. Demorou muito tempo, pois a Suprema Corte desempenhou na maior parte da história um papel de conservadora do liberalismo. Foram os ramos eletivos (Executivo e Congresso) que fizeram as políticas sociais na maior parte dos casos. A jurisprudência da Suprema Corte, em primeiro lugar, afirmou a constitucionalidade das políticas sociais declarando que a legislação sobre negócios privados (contratos e propriedade) era legal: nestes termos, permitiu o aumento do poder de polícia (police power) em contraste com os limites da propriedade e do direito adquirido da famosa V Emenda (takings clause cláusula da desapropriação). Sob esta proteção constitucional 
nasceram os programas de affirmative action, ou seja, de promoção de grupos subalternos. Em segundo lugar, foi obrigada a um verdadeiro tour de force, usando um dispositivo desenhado para proteger a igualdade formal (procedimental) na proteção de igualdades substanciais, ou como descrito por Frank Michelman, de um mínimo de bem-estar (de subsistência), reinterpretando completamente o sentido histórico do texto (Hirsch, 1992). Completando o quadro, a cláusula de regulação do comércio interestadual foi usada para dar ao Congresso competência em geral para intervir na economia nacional.

Convém distinguir duas espécies de direitos defendidos pelos movimentos sociais: os direitos à redistribuição dos ônus e benefícios econômicos da vida e os direitos ao reconhecimento da própria imagem, ao respeito devido a cada um (identidade). Embora ambos coloquem problemas relacionados ou relacionáveis à teoria da justiça, o texto que segue se restringe, o quanto possível, aos primeiros (direitos sociais de caráter econômico).

2. Uso do sistema jurídico: Direitos Sociais.

Lon Fuller (1981) investiga os limites da adjudicação (decisão judicial) como instrumento de regulação normativa. Conflitos policêntricos são os de divisão do indiviso ou do indivisível, que só podem ser terminados por formas de acordo. Isto porque o terceiro, chamado a decidir como juiz ou árbitro, não tem como escolher um argumento e uma prova de um ato. O caso é uma teia de aranha, em que uma interferência localizada não pode ser isolada do todo. Portanto, os conflitos bilaterais decidíveis pelo judiciário são de uma natureza distinta dos conflitos plurilaterais (policêntricos): plurilaterais não são os que envolvem muitos participantes, mas os que não podem ser decididos num jogo de soma zero (a vitória de um sendo a derrota de outro, mesmo parcialmente).

Os conflitos resolúveis pelo judiciário têm as seguintes características: 1. $O$ árbitro não pode ter iniciativa, seja porque aquele que já se envolve num conflito a ponto de iniciar o processo alguma idéia já tem de seu resultado, seja porque as relações adjudicáveis são de reciprocidade; neste sentido, o árbitro/juiz está obrigado a dar igual atenção aos argumentos de ambas as partes; 2. Uma decisão judicial precisa de fundamentos racionais, compreensíveis e suficientes (reasoned opinions); 3. A decisão judicial é por natureza retrospectiva (aplica-se a casos já ocorridos), refere-se a fatos passados, suficientemente provados. Em 
resumo, fatos e argumentos são materiais indispensáveis, não ponderações sobre conveniência, eficiência ou transformação/reforma.

Lieberman (1981) percebe que um número crescente de conflitos levados às Cortes apresentam diferenças estruturais com o conflito dual, de justiça corretiva ou comutativa. O modelo de Lieberman pode ser resumido no seguinte quadro:

\begin{tabular}{|l|l|l|}
\hline \multicolumn{1}{|c|}{ Componentes } & Adjudicação Tradicional & \multicolumn{1}{|c|}{ Estilo Emergente } \\
\hline ator & indivíduo identificável & $\begin{array}{l}\text { coletividade abstrata de pessoas ou } \\
\text { pessoas não-identificáveis }\end{array}$ \\
\hline tempo do ato & passado imediato & $\begin{array}{l}\text { passado distante, ou potencialmente } \\
\text { continuando no futuro }\end{array}$ \\
\hline natureza do ato & específica & $\begin{array}{l}\text { não-específica, ou variedade de atos } \\
\text { (atividade) }\end{array}$ \\
\hline ilicitude & por definição legal & sem precedente ou legislação clara \\
\hline prejuízo & palpável & intangível \\
\hline vítima & indivíduo identificável & $\begin{array}{l}\text { muitas pessoas, não necessária ou } \\
\text { diretamente o autor }\end{array}$ \\
\hline remédio provido & $\begin{array}{l}\text { estrito, diretamente rela- } \\
\text { cionado ao fato ilícito }\end{array}$ & $\begin{array}{l}\text { amplo, não necessariamente deduzível } \\
\text { da natureza do prejuízo }\end{array}$ \\
\hline efeitos & sobre as partes do caso & $\begin{array}{l}\text { sobre não-partes, milhões de pessoas } \\
\text { eventualmente }\end{array}$ \\
\hline $\begin{array}{l}\text { envolvimento da } \\
\text { Corte }\end{array}$ & $\begin{array}{l}\text { emissão de um julga- } \\
\text { mento }\end{array}$ & \begin{tabular}{l} 
envolvimento continuado \\
\hline
\end{tabular}
\end{tabular}

Os problemas de justiça distributiva num contexto de disputa institucionalmente bilateral são também percebidos por Cass Sunstein. Além das questões de eficácia e efetividade das decisões, o processo decisório judicial/arbitral impõe um limite às questões argumentáveis. "Uma decisão que exija despesas com transporte de crianças para escolas, por exemplo, pode retirar recursos de uma área com igual ou maior exigência de recursos públicos inclusive programas de saúde ou assistência e previdência para os pobres". Ressalta que o modelo judicial é fundamentalmente compensatório (corretivo): $A$ prejudica $B, B$ exige que o status quo ante seja restabelecido por uma indenização.

Nos anos 60 e 70, continua ele, a revolução dos direitos (the rights revolution) terminou por confundir duas ordens de direitos: de um lado aqueles 
reivindicados pelo movimento de direitos civis (antidiscriminatórios) e de outro os direitos da Great Society, pregada por Johnson (proteção ambiental, direitos sociais, dos consumidores, e políticas redistributivas de renda em geral). Tanto no desenvolvimento do Estado regulador a partir dos anos 30, quanto na revolução dos anos 60 e 70, o papel do judiciário foi muito pequeno, quando comparado com o do Presidente e do Congresso, que por meio da legislação, da regulamentação ou das agências governamentais independentes, deram curso a medidas de reforma social. A diferença entre a intervenção estatal nos anos 30 e nos anos 60 reside no fato de que o primeiro objetivo do New Deal era a estabilização da economia, organizando preços e restaurando a possibilidade de iniciativa econômica. A intervenção dos anos 60-70 era a proteção dos grupos desprovidos ou subordinados. Em resumo, promoção da produtividade no primeiro caso, proteção dos desprovidos, no segundo.

Em qualquer dos casos, porém, o que está em jogo nos diversos conflitos é um conflito por um bem público, ou comum cujo consumo é não excludente (razão pela qual conflitos de justiça distributiva são jogos de soma não zero). A definição de bem público ou comum usada é de Olson (1971), para quem um bem comum, ou coletivo, ou público, é aquele que, se qualquer pessoa $\mathrm{X}$, de um grupo $\mathrm{X} 1$, o consumir, não pode praticamente ser excluído do consumo de outros daquele grupo. Em outras palavras, mesmo aqueles que não pagam pelo bem não podem ser excluídos do seu consumo. "O próprio fato de que um objetivo ou fim é 'comum' a um grupo significa que ninguém daquele grupo pode ser excluido do benefício ou satisfação conseguidos por sua consecução" (Olson, 1971, p.15). Outra característica do bem comum é seu fornecimento solidário: uma vez fornecido para uma pessoa, pode ser fornecido a todos ou a muitos outros a um custo zero ou muito baixo. A saúde, a educação pública, a defesa e a segurança e a justiça têm muito desta característica: uma escola, um hospital, um tribunal, uma força policial, uma vez organizados podem ser usados por qualquer um de certo grupo (distrito, cidade, estado...) e os custos de fornecimento não são multiplicados só pelo número de beneficiários. Exemplo dramático é o da defesa nacional: uma vez organizada, ninguém pode ser excluído, pois não pode ser organizada para a defesa de um e não de outro num mesmo estado, e a proteção de um não exclui a de outro (quando o serviço é prestado publicamente: pois o serviço público pode ser apropriado privadamente por interesses específicos, resultando, claro, na deslegitimação de um processo político pretensamente democrático). 
Em direito, alguns bens coletivos, públicos ou comuns são fornecidos uti universi, e não podem comodamente ser fornecidos (nem custeados) uti singuli sob pena de exclusões ilegítimas. Por isso, o preço de um bem público pode ser dividido por meio de custos impostos a todos os membros do grupo, não sob a forma de preços contratuais. O bem público é, por natureza, indivisível. No entanto, é possível que alguém se beneficie, escapando dos custos: trata-se do efeito carona (free-rider effect). "O poder coletivo dos talentos e recursos de cada um é maior do que a simples soma dos talentos e recursos singularmente envolvidos. Cada pessoa individualmente, porém, sabe que pode ficar muito melhor se todos, menos ela, agir com vistas ao bem comum, de modo que ela possa se beneficiar do resultado sem ter que pagar pelo fardo comum. Se cada um seguir esta lógica e racionalmente optar pelo seu ganho pessoal às custas de todos os outros, não há cooperação. Todos ficarão pior. $O$ que é racional para um indivíduo é tragicamente irracional para a sociedade como um todo. (Reich, 1983, p. 280).

O uso dos mecanismos tradicionalmente associados a direitos individuais, ou o uso de categorias apropriadas ao exercício da justiça comutativa, quando o conflito é de justiça distributiva leva em geral à proteção judicial do carona. Nestes termos, o direito invocado individualmente costuma estar associado ao privilégio ou à imunidade de certas imposições gerais cujo objetivo é distribuir os custos de um bem comum, ou forçar a contribuição para um bem comum que de outra forma seria inalcançável ou infactível. A imposição de certos custos e o impedimento do efeito-carona vistos positivamente são imposição de comportamentos cooperativos, que só fazem sentido se gerais (ninguém quer ser o único a pagar a conta, mas se houver alguma garantia de que todos vão pagar a sua parte - por obrigação legal, devidamente imposta, cumprida e executada, existe uma unanimidade hipotética, racional, pensável e desejável: cada um paga apenas sua parte).

Os limites à decisão judicial no que diz respeito a políticas públicas, mais especificamente sobre bens comuns ou coletivos (indivisíveis e inapropriados ou inapropriáveis individualmente), derivam da natureza do processo e dos bens, não apenas de fatores empíricos (como a cultura dos juízes ou os recursos materiais à disposição dos tribunais).

Rosenberg (1991) elenca alguns obstáculos institucionais-estruturais ao desempenho do sistema judicial em questões de políticas públicas, sobretudo quando inovadoras, reformadoras, desafiadoras da neutralidade presumida do status 
quo jurídico. Em primeiro lugar a natureza limitada dos direitos constitucionais: essencialmente quer dizer que os direitos individuais são suscetíveis de adjudicação, enquanto as reformas só podem ser levadas a cabo num processo de deliberação. Em segundo lugar, os tribunais são menos independentes do que se imagina: ainda que sejam relativamente isolados politicamente dos outros poderes, a tendência é que reproduzam a visão do senso comum, a visão majoritária, a mainstream public opinion. Em terceiro lugar, quando escapam à perspectiva tradicional podem efetivamente decidir a favor de reformas sociais, mas neste caso não dispõem de meios institucionais (não se trata de recursos materiais) para implementar a reforma: a independência dos juízes é um obstáculo institucional, pois se um tribunal superior decide a favor de uma reforma, o juiz de primeiro grau pode retardar e de fato dificultar a execução da medida. Se o juiz de primeiro grau for criativo, o tribunal pode reformar sua decisão. A falta de poder de iniciativa (ne procedat iudex sine auctorem) retira do judiciário a possibilidade de estabelecer uma agenda, uma política, isto é, um conjunto de atos determinados para atingir um certo objetivo. Os tribunais, por definição, num sistema republicano, democrático e não-inquisitorial, são privados do poder da espada e da bolsa (lack the sword and the purse): ora, uma reforma social exige alocação de recursos, que os tribunais são proibidos de fazer pela appropriation clause da Constituição (proibindo que o Tesouro faça qualquer pagamento sem que haja autorização legislativa).

Analisando o envolvimento da Corte Suprema na defesa dos direitos civis dos negros, Rosenberg demonstra que entre 1955 e 1968 ela decidiu apenas três casos relativos a segregação racial: Cooper v. Aaron (1958), Goss v. Board of Education of Knoxville (1963), Griffin v. Prince Edward County (1964). No período, foi com muita parcimônia que a Corte agiu, assim como os tribunais inferiores em geral. A decisão famosa, de 1954, no caso Brown v. Board of Education of Topeka, dado o caráter descentralizado e dada a ausência de poder de controle da Suprema Corte (exceto por revisão em certiorari) sobre o desempenho dos outros tribunais, não significou mudanças gerais no sistema educacional segregado. Mas em 1964 foi sancionada lei de direitos civis (Civil Rights Act), em cuja execução se empenhou o Congresso e sobretudo o Executivo (Presidente Johnson). Na avaliação final, entre 1954 e 1964 a Suprema Corte pronunciou-se quatro vezes, com resultados muito modestos: a partir de 1964, com a ação concertada do executivo e do legislativo foram destinados fundos para o processo de de-segregação, que deslanchou desde então. A consideração geral de Rosenberg é 
clara: o uso de test cases traz à tona o problema político da segregação dos negros; mas o efeito político generalizado só pode ser obtido por meio de políticas públicas determinadas pelo executivo e pelo legislativo.

Michelman (1969), alerta para as dificuldades de uma estratégia adotada tipicamente pela Suprema Corte: a proteção de direitos sociais por meio da Emenda Constitucional n. 14, essencialmente uma emenda antidiscriminatória, incorporada à Constituição no período pós-guerra civil. Segundo ele, a estratégia judicial, adotada seja por advogados, seja pela Suprema Corte, consistia em considerar discriminatória qualquer prática que impedisse aos pobres igual acesso a determinados bens (voto, educação, etc). Neste sentido, a discriminação contra a pobreza seria comparável à discriminação contra a cor. Para Michelman, tal estratégia incorria em certos equívocos conceituais, só corrigíveis mediante o reconhecimento puro e simples do direito ao mínimo de satisfação de necessidades básicas. Desta forma, o que os "pobres" poderiam reivindicar não seria apenas um tratamento igual, o que implicava comparar sua satisfação com a de outros, mas um mínimo objetivamente determinável, independente de comparações. Na avaliação de Michelman, seria preciso reconhecer que a desigualdade econômica é repugnante aos princípios constitucionais republicanos, pois o Estado deveria proteger contra os efeitos endêmicos e aleatórios na economia por razões semelhantes às usadas para promover a segurança pública.

No entanto, a adoção deste conceito de direito a um mínimo de necessidades satisfeitas, antes que o direito a tratamento igual, demandaria remédios (soluções) que o judiciário não poderia adequadamente conceder (por falta de padrões decisórios justiciáveis, ou porque tais direitos exigiriam medidas de ação positiva, política pública).

A própria natureza dos bens públicos buscados num programa governamental podem ser um obstáculo à sua consecução pelo mecanismo tradicional do processo judicial. Os programas regulatórios buscam diminuir os riscos em massa, probabilística e estatisticamente: trata-se de zelar por um bem coletivo, como a saúde pública. Um bom programa de saúde pública ou de segurança no trabalho pretende diminuir a incidência geral de uma doença ou de acidentes do trabalho numa classe determinada de serviços, mas não pode pretender eliminar os riscos individuais. Para isso deve haver um sistema de seguros (público ou privado), como raciocina François Ewald. 
3. Três exemplos: Gold Clause Cases (1935), Wyatt Cases (1970), California V. Us (1995).

Os três exemplos a seguir utilizados servem para ilustrar as dificuldades do processo judicial tradicional diante de casos de justiça distributiva. Nos três casos a seguir analisados, o interesse ou direito disputado é indivisível (o valor da moeda, ou a moeda como tal, um serviço público de saúde mental; uma polícia de fronteiras nacionais), a decisão refere-se à continuidade de um serviço ou bem público (uti universi), as partes no processo não representam adequadamente os interesses possíveis sobre o bem, o direito ou a coisa (o conflito é policêntrico: qualquer usuário de moeda no primeiro caso como credor ou devedor -, todos os envolvidos no sistema de saúde no segundo caso pacientes dos hospitais, mas também os servidores e médicos, além de qualquer beneficiário do sistema de saúde -, todos os outros estados da União, no último caso).

3.1. Gold Clause Cases. Em 1935, a Suprema Corte foi chamada a decidir a constitucionalidade da reforma monetária efetivada por Roosevelt. Em março de 1933, o sistema monetário norte-americano enfrentou certas circunstâncias que se consideraram de emergência. Havia em poder do público um volume de títulos do Tesouro federal emitidos com a cláusula-ouro: os títulos poderiam ser resgatados seja em dinheiro seja em ouro, na proporção fixa de 25 e 8/10 grains de ouro, de 9/10 de pureza (U\$ 20,67 por onça). Esta cláusula era comum também em numerosos títulos emitidos por companhias privadas (bonds). Desta forma, o mercado financeiro encontrava-se vinculado fixamente ao padrão-ouro numa quantia determinada. A cláusula-ouro funcionava como um indexador, dando aos credores do Tesouro federal e dos devedores privados uma garantia contra a desvalorização da moeda. Em fevereiro de 1933 houve uma corrida pelo resgate dos títulos em ouro, ao mesmo tempo em que houve uma retirada crescente do ouro depositado. O objetivo era a compra de moeda estrangeira estável (a maioria das moedas européias já havia abandonado o padrão-ouro) ou a remessa do ouro para o exterior. Segundo os números apresentados no debate oral perante a Suprema Corte a disponibilidade de ouro à época era equivalente a 4 bilhões de dólares nos Estados Unidos, 11 bilhões de dólares no mundo; o total de títulos emitidos com cláusula-ouro nos Estados Unidos chegara a 100 bilhões de dólares. Claramente seria impossível resgatar todos os títulos em ouro: quem primeiro chegasse levaria seu depósito, os restantes ficariam privados do benefício do indexador. Os detentores dos títulos sem 
cláusula-ouro, por seu turno, corresponderiam a uma fração do público desprovida de toda defesa contra o processo inflacionário. Entre $1^{\circ}$ de fevereiro e 5 de março de 1933 houve uma retirada de U\$ 476,1 milhões de dólares de depósitos e resgates de títulos. Diversos bancos quebraram.

Diante de tais circunstâncias, o presidente Roosevelt decretou um feriado bancário em 6 de março (uma sexta-feira) e na segunda-feira, 9 de março de 1933, sancionou o Emergency Banking Act, que conferia poderes ao executivo para regulamentar o sistema financeiro, o mercado cambial e a bloquear os depósitos (freezing of all gold deposits), exportação ou armazenamento (posse) particular de ouro. Em 5 de abril, por decreto executivo, todos os títulos contendo cláusula-ouro passaram a ser resgatados por seu valor nominal em dólares, exclusivamente. Em 12 de maio foi sancionado o Agricultural Adjustment Act, impondo o poder libertário do dólar para todos os contratos e autorizando o presidente a reduzir o valor do dólar em relação ao ouro. Em 5 de junho, o Congresso aprova uma Resolução-Conjunta (Joint Resolution) que dispõe entre outras coisas: a. qualquer cláusula que estipule o pagamento em ouro ou em outra moeda especial, que não o dólar, é declarada contra a política pública (public policy); b. todas as obrigações, anteriores ou posteriores à Resolução, seriam pagas dólar por dólar, valor nominal, em débitos públicos ou privados; c. o termo obrigação inclui qualquer obrigação pagável em dinheiro, pública ou privada, exceto o meio circulante. Em 28 de agosto, o presidente emite um novo decreto regulando os depósitos em ouro. Em 30 de janeiro de 1934 é sancionado o Gold Reserve Act, pelo qual o secretário do Tesouro é instruído a derreter todas as moedas de ouro, autoriza-se o resgate dos depósitos de ouro no dólar-ouro apenas para o pagamento de negócios internacionais. Finalmente, em 31 de janeiro de 1934, o presidente desvaloriza o dólar, passando a valer 15 e 5/21 grains de ouro puro (9/10), ou U\$ 35,00 por onça. A desvalorização equivale a $69,32 \%$.

Em aproximadamente um ano foram tomadas medidas que equivaleram a retirar o ouro de circulação (obrigando o seu depósito), congelamento de todos os depósitos em ouro, anulação de todas as obrigações (públicas e privadas) indexadas em ouro, resgate de todos os depósitos ou títulos pelo valor nominal em dólar e, finalmente, a desvalorização do dólar em relação ao ouro.

O caso chega à Suprema Corte por meio de um writ of certiorari na disputa entre Norman v. Baltimore \& Ohio Railroad (procedente de Nova Iorque) e de United States Et Al. v. Bankers Trust Co et al. Na mesma ocasião, a Suprema 
Corte instrui por Certificate duas U.S. Court of Claims nos casos Nortz v. United State e Perry v. United States. As decisões conjuntas são dadas em 18 de fevereiro de 1935, depois de ouvidas as sustentações orais entre 8 e 10 de janeiro, no ano judiciário iniciado em outubro de 1934 (US 294, 240-381), ficando conhecidas como Gold Clause Cases.

Pela inconstitucionalidade das medidas de reforma monetária, argumentava-se em resumo o seguinte. O Congresso não dispunha de poder para aumentar ou diminuir as obrigações contratadas entre particulares; a cláusula-ouro era parte de um negócio contratual e não uma moeda; seu objetivo era simplesmente determinar mais precisamente um valor de troca; qualquer objeto podia ser usado como medida de qualquer coisa, inclusive o ouro; apenas as leis falimentares (Constituição, art. I, Sec. 8, 4) poderiam alterar as cláusulas de pagamento de um contrato; o poder de emitir moeda não incluía a determinação de obrigações entre credor e devedor; a Resolução do Congresso era uma desapropriação ou confisco do credor sem indenização, contrária ao direito de propriedade protegido pela $\mathrm{V}$ Emenda da Constituição; se a proibição da cláusula-ouro era necessária para o bem comum (público), os prejudicados haviam sido afetados por uma desapropriação e faziam direito a uma indenização e afinal o resultado das medidas havia sido a transferência de propriedade da classe dos credores para a classe dos devedores. Bankers Trust Co. argumentou que a cláusula-ouro era conhecida desde sempre; os contratos, quando feitos, eram perfeitamente legais e válidos; a Resolução do Congresso ultrapassava os poderes de tomada de empréstimo previstos na Constituição e aqueles relativos à emissão de moeda; o propósito do Congresso havia sido a desvalorização da moeda e respectivamente a redução do valor das obrigações; se o Congresso estivesse autorizado a fixar o poder aquisitivo da moeda, estaria também autorizado a fixar todos os preços; a situação de emergência poderia obrigar um país a declarar sua incapacidade de pagar suas obrigações, mas não de repudiar seus débitos; a constitucionalidade daquela Resolução significaria que o Congresso, a qualquer momento, poderia destruir todos os contratos; finalmente, a Resolução-Conjunta significava simplesmente que a propriedade de uma pessoa (o credor) estava sendo transferida para outro particular (o devedor).

Pela constitucionalidade da medida foram apresentados os argumentos seguintes. A constitucionalidade dos atos do Congresso é sempre presumida, o que se exige da coordenação dos poderes do Estado; o Congresso detinha um poder discricionário sobre a regulamentação do sistema monetário, a menos que esta se 
revelasse claramente arbitrária, caprichosa e irracional (arbitrary, capricious and unreasonable). Ora, as condições de 6 de março de 1933 eram extraordinárias: bancos estavam falindo e apenas o dólar, ao lado do franco suíço e do florim holandês, não havia sido desvalorizado em relação ao ouro. A sequiência de atos do presidente e do Congresso demonstravam que não se tratava de medidas arbitrárias ou caprichosas, mas de uma verdadeira política orientada, conjunta e harmoniosamente determinada pelo executivo e pelo legislativo. Por outro lado, se a Suprema Corte aceitasse os argumentos dos autores estariam elevando o total de obrigações em moeda em mais de U\$ 69 bilhões e reduzindo o saldo do Tesouro em mais de 2,5 bilhões de dólares, aumentando sua dívida em 10 bilhões de dólares. Os argumentos dos credores eram pela inviolabilidade dos contratos, enquanto que o governo tinha o direito de zelar por sua própria subsistência (self-preservation), o que um contrato escrito entre particulares não poderia impedir; o ouro não é uma mercadoria qualquer, e neste sentido os contratos com cláusula-ouro interferiam com a competência federal. A Resolução-Conjunta não era uma desapropriação, apenas frustrara objetivos privados incompatíveis com o exercício do poder soberano nacional, desapropriação e frustração sendo coisas diferentes. A alegação de que o propósito da Resolução era transferência de propriedade era irrelevante e imaterial. Ora, os contratos particulares só podem ser interpretados tendo como pano de fundo a existência de um poder soberano nacional, como postulado de qualquer ordem jurídica. Os valores são coisas relativas, por isso o poder de regular o valor da moeda, previsto na Constituição, só poderia significar uma atividade contínua, não a fixação de uma medida determinada. Se a Resolução fosse invalidada, a moeda dos EUA não teria o mesmo valor para todos, nem para todos os débitos: a cláusula-ouro era um obstáculo à paridade, e continuar a sua existência significaria preferir os direitos dos credores de gold certificates aos outros credores em geral, pois em fevereiro de 1933 era impossível resgatar a dívida pública nos valores em ouro; e isto implicaria, rejeitada a Resolução, a resgatar a dívida em ouro até que as reservas se esgotassem, denegando tratamento igual a todos os credores (algo que na tradição do direito romano-canônico chamamos de par conditio creditorum). A cláusula-ouro havia se transformado num obstáculo à capacidade do Tesouro de tomar empréstimos e ao mesmo tempo criava uma classe privilegiada de credores, detentores de 20 bilhões de dólares em títulos federais, aos quais estaria sendo dada uma imunidade, por força de um contrato, às necessidades gerais da justiça e do direito. O poder de emitir moeda e regular seu valor pertence por natureza ao iura 
maiestatis. Estes argumentos foram apresentados pelo procurador-geral dos Estados Unidos. Foram em seguida complementados pelo advogado da Reconstruction Finance Corporation, que em resumo acrescentou o seguinte. As cláusulas-ouro anulavam o poder do Congresso de estabelecer uma moeda uniforme e o legislativo dispunha de poder para declarar inválidas todas as disposições cujo objetivo era frustrar o exercício dos poderes constitucionalmente estabelecidos.

A Corte inicia suas razões afirmando que a decisão que lhe cabe é sobre os poderes (competência) e não sobre a política do Congresso. Quando contratadas, as obrigações de cláusula-ouro não implicavam ilegalidade. Seria preciso examinar, pois, a competência do Congresso para estabelecer o sistema monetário, para anular disposições de contratos existentes e analisar se a cláusulaouro era uma interferência dos particulares na esfera de competência congressual. Um primeiro argumento da Corte esclareceu que a propriedade do ouro ou da prata era sujeita a limitações especiais, pois o ouro e a prata cunhados têm um valor diferente de seu valor intrínseco: seu poder liberatório. Este advém da lei. Por isso o poder de cunhar (e emitir) moeda inclui o poder de regular (proibir a destruição, exportação, etc.) de ouro e prata. Além disso, o Congresso pode, em geral, legislar sobre obrigações: a legislação de falências é um caso típico, diz a Corte (em que se diminui a exigibilidade dos créditos), mas em tempos de guerra, por exemplo, pode proibir transações com nações inimigas, ou mesmo em tempo de paz pode impor restrições ao comércio. A proteção constitucional contra desapropriação ou confisco limita-se à desapropriação direta, não a qualquer perda ou prejuízo: por exemplo, um aumento de imposto ou de tarifa é uma perda, mas "quem jamais suporia que por causa disto uma tarifa não poderia ser aumentada, ou uma lei impondo embargo ou proibição de negócios ser promulgada, ou uma guerra ser declarada?" Ora, no caso o efeito da lei tinha sido que todos os credores haviam perdido alguma coisa, mas em geral todos tiveram a mesma perda. Os contratos com indexação tratavam do estabelecimento da moeda, por isso lidavam com matéria da competência do Congresso: tinham uma congenial infirmity. Não se encontrava fundamento constitucional para impedir o Congresso de proibir contratos ou cláusulas, de outro modo a autoridade federal estaria sujeita - quanto aos seus poderes de regular o comércio interestadual ao que dispusessem as partes de um contrato. No entender da Corte a ação do Congresso também não era caprichosa ou arbitrária: correspondia de fato a uma política determinada, e, neste sentido, não-sujeita à revisão judicial. Segundo a maioria, as medidas haviam alterado o sistema monetário: na nova moeda 
os estados, as cidades, as companhias de estrada de ferro, as concessionárias de serviços públicos iriam receber suas rendas, e não seria possível aceitar que tais recebimentos estivessem sujeitos à nova legislação e controlados pela nova moeda, enquanto as obrigações a serem pagas estivessem regidas por outra lei e pela antiga moeda. Se assim fosse, os devedores seriam obrigados a pagar um dólar e 69 centavos e a receber apenas um dólar de outro lado. A Corte, diz a maioria, não pode lidar com as conseqüências individuais de políticas gerais: no Congresso reside de fato o poder de legislar sobre moeda e a manutenção da cláusula-ouro nos contratos seria permitir que os particulares executassem contratos interferindo diretamente nos poderes do Congresso. E a interferência do Congresso nos contratos, por outro lado, não fora caprichosa (arbitrária), com desvio de poder. ${ }^{1}$

1. O contraste com as decisões da justiça federal brasileira no caso da reforma monetária de 1990 não poderia ser maior. Até hoje, a grande maioria dos tribunais julgou o "Plano Brasil Novo" do ponto de vista exclusivamente individual e contratual. Algumas decisões consideram o caso como dever de indenizar do Estado, o que resulta num paradoxo insolúvel: se o Estado deve indenizar a todos pela perda do valor da moeda, quem são os que pagam por isso, se não todos? Por isso, aliás, a razão impõe a regra, até hoje nunca desafiada, de que os prejuízos universais não são indenizáveis. Poucos foram os juristas que mostraram o caráter eminentemente público da reforma monetária, entre eles contandose: Letácio Jansen (A face legal do dinheiro. Rio de Janeiro: Renovar, 1991), Diogo de Figueiredo Moreira Neto ("A reforma monetária e a retenção dos ativos líquidos no Plano Brasil Novo", Revista de Informação Legislativa, 108 (49:66)) e Gilmar Ferreira Mendes ("A reforma monetária de 1990 Problemática jurídica da chamada 'retenção dos ativos financeiros'", Revista de Direito Administrativo, 186 (26:92), 1991). Segundo Gilmar Ferreira Mendes o TRF da $3^{\mathrm{a}}$ Região só pôde dizer que a reforma monetária era um "nada jurídico" porque se recusou a enquadrá-la naquilo que ela realmente era, deixando de considerar os argumentos de sua natureza monetária-financeira e recusando-se a perceber que o exercício do direito constitucional de propriedade faz-se conforme a natureza do bem: a propriedade sobre um lote de terras é distinta da propriedade sobre um crédito. Os tribunais federais recusaram-se a dar validade à desindexação do Plano Brasil Novo caso a caso: deste modo, hoje existem créditos indexados e desindexados, sendo que há várias decisões aceitando, por exemplo, que os salários deveriam ser desindexados. O tratamento desigual (não-isonômico) é provavelmente uma das consequiências mais graves da outorga de poder ao juiz singular para decidir questões de políticas sociais distributivas ou compensatórias. Sobre o assunto, houve um debate clássico a respeito da desindexação na Alemanha de Weimar também (cf. Nussbaum, 1939 e 1950). Em resumo, a Suprema Corte entendeu que o caso era de um bem público: por isso, descartou a interpretação, hoje corrente em algumas jurisdições federais brasileiras, de que se tratava de milhões de contratos entre o Estado e cada um dos cidadãos. A situação era plurilateral: o fundo comuın (não uma pessoa, o Estado) e todos os participantes do fundo comum (cidadãos), simultaneamente credores (pela moeda e pelos títulos) e devedores (pelos impostos e preços) não apenas do fundo, mas através deste fundo, uns dos outros. Especialmente nos lugares onde a voz do poder econômico tende a ser mais forte é notável que a solução seja dada em termos individuais contratuais, e que o resultado seja o benefício de alguns (exportadores indenizados por desvalorizações cambiais, companhias aéreas indenizadas por congelamento de tarifas, etc) em detrimento de muitos. 

(M.D. Ala. 1972), 325 F. Supp. 781, 344 F. Supp. 1341 (M.D. Ala. 1972); Wyatt v. Aderhold, 503 F.2d 1305 (5th Circuit. 1974). Esta série de casos ilustra um dos dilemas da busca do judiciário para a solução de casos dramáticos de políticas públicas, numa confluência de problemas que vão dos direitos civis e garantias individuais até a administração de um sistema de saúde. A ação iniciou-se em 23 de outubro de 1970 e, em abril de 1972, um juiz federal determinou aos hospitais psiquiátricos do Estado do Alabama o cumprimento de uma ordem de mais cinqüenta itens específicos, de modo a se adequarem a limites de higiene, salubridade, segurança e saúde para os internos. Os internos eram pessoas mantidas sob custódia por medida de segurança, ou seja, incapazes e inimputáveis que não poderiam ser condenados e submetidos a penas nas prisões estaduais. Do ponto de vista dos direitos civis os pacientes não poderiam ser privados de sua liberdade sem o devido processo legal, só poderiam ser mantidos internados (contra sua vontade) por motivos de saúde. Se os hospitais estavam num estado de penúria, sem dar tratamento adequado, seria o caso de liberar seus pacientes. A alternativa seria cumprirem os padrões determinados pelo juiz.

O caso se transforma na administração dos hospitais pelo judiciário pela própria natureza da lide. No caso, as vítimas não queriam indenização, queriam uma mudança de atitude (por parte do governo e por parte da administração do hospital), queriam um estado diferente de coisas para o futuro. O caso poderia ter um impacto político. Jethro Lieberman (1981) fala da Síndrome da Intervenção Federal no Alabama, isto é, a característica daquele estado de só permitir o exercício dos direitos civis sob a ameaça de intervenção federal. Assim, os juízes federais davam ordens, que os potentados políticos locais não cumpriam, dando vez à intervenção federal. Neste jogo de cena, os juízes federais participavam indiretamente permitindo que os políticos locais se apresentassem a seus eleitores (brancos, conservadores, racistas, etc.), dizendo-se vítima do governo federal, jamais assumindo a responsabilidade por políticas antipopulares, que nunca eram votadas ou implementadas na esfera estadual.

O problema tipificado nos casos Wyatt é o da impossibilidade de uma instituição desenhada para dirimir certos conflitos bilaterais sobre fatos precisos e passados desempenhar-se bem em outra qualidade de conflito. Por exemplo, o juiz proibiu que os internos trabalhassem, pois entendeu que se configurava trabalho forçado: com o passar do tempo, os próprio peritos que acompanhavam o caso 
concluíram que, sem trabalhar, os internos estavam piorando de saúde. Logo depois apresentou-se a questão dos recursos financeiros, materiais e humanos: para cumprir a ordem judicial seria preciso aumentar consideravelmente o orçamento dos hospitais, contratando pessoal, reformando os edifícios. Mas o juiz não tinha condições de propor emendas ao orçamento, ou mesmo fazer um rascunho ou uma proposta orçamentária que viabilizasse sua ordem, junto com todas as outras prioridades do estado. Poderia o juiz, para fazer cumprir sua decisão, sentenciar um aumento dos impostos? Finalmente, o próprio número de médicos empregados pelo Estado do Alabama seria insuficiente para cumprir a ordem judicial: para prover os hospitais psiquiátricos de médicos, conforme determinado pelo juiz, seria preciso deslocá-los de outras funções e até de áreas rurais e pobres do interior do estado. A saída foi começar a dar ordens para liberar pacientes. De qualquer maneira, o efeito político foi sendo aos poucos ampliado: entre 1971 e 1975 o orçamento estadual, votado pelo legislativo, triplicou as despesas com saúde pública.

3.3. O terceiro caso diz respeito à ação proposta pelo Estado da Califórnia, seu governador e outros, contra os Estados Unidos da América e outros (Caso n. 940674-K (CM), na United States District Court, Southern District of California, Western Region, em San Diego, CA). A ação proposta, em 29 de abril de 1994, foi julgada em 13 de fevereiro de 1995. Os fatos e pedidos formulados eram os seguintes: 1. que o Estado da Califórnia estava sendo objeto de uma invasão de imigrantes estrangeiros (mexicanos) que era dever da União impedir; 2. que por força de tal invasão havia sido obrigado a prover assistência médica de emergência que deveria sèr paga pelo governo dos EUA; 3. pedia-se o reembolso das despesas havidas com o encarceramento de tais estrangeiros ilegais, que haviam cometido crimes definidos pelo direito californiano; 4 . pedia-se também ordem para que a União repatriasse imediatamente os imigrantes estrangeiros ilegais; 5. requeria-se declaração de que os EUA não mantinham a guarda dos estrangeiros liberados das prisões do estado; 6. requeria-se ainda declaração de que o procurador-geral dos EUA havia de fato deixado de cumprir seu dever de acusar e processar os que tentavam ilegalmente atravessar a fronteira repetidas vezes (repeat border crossing offenders); 7. pedia-se que fosse declarada a obrigação de a União repatriar os imigrantes estrangeiros, não até a fronteira, mas até sua destinação final no interior do México; 8. finalmente, exigia-se o reembolso das despesas com educação de filhos dos imigrantes ilegais. 
A Corte Distrital para o Sul da Califórnia decidiu pela improcedência da ação. A decisão principia citando a regra estabelecida pela Suprema Corte em Lujan v. Defenders of the Wildlife (112, S.Ct. 2130-1992) segundo a qual, quando o prejuízo alegado ou sofrido pela vítima deriva de regulamentação ou falta de regulamentação da atividade de terceiros, a indenização é devida pelos terceiros, não pelo governo que a regulamenta. A partir deste primeiro enquadramento, a Corte decreta a improcedência dos pedidos, justificando-se especificamente. Quanto à alegada invasão, entende que os imigrantes ilegais não invadem o território da Califórnia no sentido constitucionalmente previsto, que exigiria a proteção da União (defesa nacional): o caso é de política de imigração, não um caso de ocupação militar ou insurreição. Ora, a política de imigração depende do poder dos Estados Unidos (União) controlarem-na. Assim, de um lado a cláusula da invasão não cria, para o Estado da Califórnia, um direito justiciável (justiciable right), que possa ser exercido por via judicial, de ver-se livre de imigrantes ilegais. Toda a política imigratória, diz o juiz, é não-adjudicável, e está totalmente nas mãos do Congresso e do Executivo. Inexiste um padrão judicial pelo qual se possa julgar a partir de que momento uma imigração se transforma em invasão. Para julgar o caso, o tribunal seria obrigado a "rever na totalidade a execução (enforcement) das leis de imigração para determinar quais as alocações orçamentárias e quais as medidas de execução que deveriam ser tomadas." Mas, de acordo com a decisão de 20 de dezembro de 1994 de outra Corte Federal (Flórida), "o juiz não tem capacidade para identificar os critérios para a tomada de tais decisões. Isto é claramente algo fora da jurisdição do judiciário." No sistema de separação de poderes norteamericano (checks and balances) decisões desta natureza pertencem ao Executivo e ao Legislativo.

No que diz respeito ao reembolso das despesas médicas com imigrantes ilegais, a decisão precisaria, em primeiro lugar, declarar que o sistema federal de auxílio-saúde é inconstitucional ou que a adesão da Califórnia ao sistema foi coagida pelo governo federal. No entanto, a Califórnia aderiu ao programa e não o denunciou: vem se beneficiando de enormes repasses federais na área da saúde e seu desligamento do programa deveria ser feito pelos órgãos competentes do próprio sistema republicano de governo da Califórnia, isto é, seu Executivo e seu Legislativo.

Quanto aos custos com encarceramento de imigrantes ilegais, a Califórnia não tem ação contra os Estados Unidos, pois se trata de fazer cumprir suas 
próprias leis (o sistema criminal é descentralizado nos EUA). Por outro lado, e este argumento é central na decisão, o valor alocado orçamentariamente para o Departamento de Justiça para a Política de Imigração, não pode ser redirecionado pelo Judiciário. A Suprema Corte já definiu a regra, segundo a qual uma quantia destinada globalmente a um departamento ou uma agência do Executivo deve ser deixada ao critério da agência, para que esta julgue as circunstâncias em que melhor poderá cumprir suas funções definidas em lei. O judiciário não pode simplesmente emitir uma ordem mandando o procurador-geral (nos Estados Unidos, o chefe do Departamento de Justiça) tomar uma atitude e fazer um desembolso que, por lei, depende de sua discrição.

O pedido de que o Departamento de Justiça seja julgado responsável por não dar cumprimento à norma do 8 USC 1252 (a) (d), que impõe a deportação de estrangeiros culpados de crimes, também não pode ser acolhido, pois a determinação ali contida é uma simples diretiva (instrução) ao procurador-geral, conforme o próprio Congresso especificou (Immigration and Nationality Technical Correctons Act, de 1994). A Califórnia não tem, portanto, um direito subjetivo propriamente contra o procurador-geral. Já quanto aos outros pedidos, relativos ao não-aprisionamento de certos imigrantes, ou acusação criminal de outros, em geral, não-só a matéria cai outra vez no âmbito da discricionariedade do Departamento de Justiça, como também a execução limitada (partial enforcement) não significa ausência de ação. Do contrário o judiciário seria obrigado (ou autorizado) a determinar quais as prioridades de execução o Executivo deveria escolher, dada a limitação de meios do procurador-geral. O Tribunal Federal do $9^{\circ}$ Circuito já decidiu que "a execução limitada e discricionária de certas tarefas não significa recusa de execução" No que diz respeito ao repatriamento apenas até a fronteira, dada a soberania do país vizinho, México, na verdade o máximo que o Departamento de Justiça pode realmente fazer é pagar uma passagem de ida até a destinação final do deportado ou repatriado, mas não mais que isso. Finalmente, no que diz respeito aos custos com a educação de filhos de imigrantes ilegais, o caso escapa totalmente à perspectiva da ação: o dever do Estado da Califórnia de propiciar tal educação procede da Constituição (cláusula de proteção igual), conforme definidos no caso Plyler v. Doe. Finalmente, a ação encontra obstáculo na chamada sovereign immunity clause e na appropriation clause da Constituição como definiu a Suprema Corte, "na ausência de apropriação especifica (orçamentária, pelo Congresso e Executivo), as Cortes federais não têm competência para ordenar 
pagamentos em dinheiro na forma de reembolsos" (City of Houston v. Housing and Urban Development). Com base em tudo isto, os pedidos de número 1, 2, 3 e 8 ficaram também indeferidos pela imunidade de soberania.

3.4. Os casos são significativos de seus respectivos momentos históricos. Seguindo a classificação de Sunstein, percebe-se que os Gold Clause Cases dizem respeito à intervenção do estado na economia para fins de estabilização. O segundo caso, Wyatt Cases, diz respeito a direitos civis, pois está fundamentado na liberdade individual (direito a não ser encarcerado sem o devido processo legal), mas também a direitos sociais (direito à saúde e aos serviços públicos). Finalmente, a disputa no terceiro caso envolve a devolução de poder aos estados (desnacionalização das questões sociais) ou descentralização, os problemas de uma sociedade pluriétnica e a definição de políticas públicas (de imigração, envolvida com Direito Internacional da nova geração liberdade de locomoção dentro de grupos econômicos, Nafta no caso). E em todos os três alguma forma de bem público ou coletivo está em disputa. No primeiro caso, o dinheiro enquanto bem público; no segundo, o sistema de justiça e de saúde, e no terceiro caso a autonomia de uma comunidade (o Estado da Califómia) em relação a outra (União).

Os três casos, ou melhor, as três séries de casos, colocam o problema central de uma teoria da justiça distributiva. Há argumentos de natureza jurídica que se relacionam diretamente com os temas da teoria da justiça. O primeiro é o do tratamento igual; o segundo é o da natureza do valor do dinheiro (bem público, indivisível); o terceiro é do equilíbrio entre liberdade individual e poderes da autoridade política. Os três casos colocam diante do judiciário conflitos de caráter plurilateral, policêntrico, ou seja, de alocação entre várias partes de recursos escassos ou indivisíveis, e não de retribuição ou indenização.

Os argumentos no caso da cláusula-ouro podem ser alinhados em termos de defesa dos critérios de justiça comutativa e dos critérios de justiça distributiva, conforme se encare a natureza do bem e do conflito. $\mathrm{O}$ argumento dos credores de títulos com cláusula-ouro trata a matéria do ponto de vista da justiça comutativa. Para eles, a regulação interfere na propriedade privada e nas promessas. Nitidamente, a questão está colocada do ponto de vista de um bem perfeitamente identificado, individuado e divisível (seu crédito) que pode ser objeto de uma alocação definida em termos de troca: se o governo pretende extirpar a cláusula-ouro dos contratos, que pague (indenize) os credores, de outra forma, como alegam, estaria simplesmente transferindo propriedade de credores para devedores. 
$\mathrm{O}$ argumento do governo, pelo procurador-geral dos EUA e pela Finance Reconstruction Corporation, vai na linha da justiça distributiva. Neste sentido, a extinção da cláusula-ouro vale para todos ou não-vale para ninguém: se houvesse a pretendida indenização estaria ocorrendo uma preferência de um grupo de credores sobre outros, pois seriam pagos todos os débitos (públicos e privados) até que fossem satisfeitos os contratos com o indexador ouro, enquanto que os credores de dólares sem indexação ficariam a ver navios, seriam satisfeitos apenas se sobrassem reservas no Tesouro federal, por exemplo. O governo argumenta que o conflito é de caráter distributivo, e não-comutativo: dada a impossibilidade de resgate simultâneo de todos os títulos indexados, o seu pagamento com o indexador implicaria tratamento privilegiado dos detentores de papéis e contratos corrigidos pelo padrão-ouro. Era uma situação falimentar, de fato: por isso os dois lados referem-se à possibilidade, constitucionalmente reconhecida, de o Congresso legislar sobre falências e determinar rateios e pagamentos de forma diversa da prevista nos negócios originais, feitos quando o devedor está in bonis. Ninguém questiona a possibilidade de tal legislação, pois a falência é tipicamente uma situação de conflito policêntrico, em que o patrimônio do devedor se transforma em massa indivisa (uma universalidade) para satisfazer a todos os credores ao mesmo tempo, conforme suas classes e privilégios, mas na qual ninguém tem, em princípio, direito ao seu próprio crédito, senão ao pagamento na moeda da falência (rateio).

A Suprema Corte dá outra fundamentação para legitimar e manter a reforma monetária de Roosevelt. Apela para o caráter de bem público do dinheiro. Este caráter provém do fato de que o ouro e a moeda não têm valor apenas intrínseco ou de uso: são instrumentos de troca. Mas, diz a Corte, são instrumentos de troca apenas porque há uma autoridade que os define: não são as partes de um contrato que fazem uma moeda, é a comunidade ou a autoridade. As partes aceitam o ouro, ou o dólar, porque sua aceitação universal como instrumento de pagamento é imposta pelo soberano, pela autoridade pública, pelo governo. Por isso, diz, seu poder liberatório não vem da escolha individual das partes, pois não se trata de simples troca de mercadorias, mas de pagamento. E poder liberatório só existe quando a expectativa geral de aceitação é dada pela lei. Nestes termos, o dinheiro é objeto de regulação pública, é bem público, e indivíduos singularmente considerados não podem, por via de contrato, determinar este bem: ao assim fazerem, interferem num campo, pør natureza, pública, e suas convenções aí têm uma debilidade intrínseca. A Suprema Corte reconhece que a aceitação de um instrumento de troca é 
uma qualidade originada não pela soma de muitos contratos individuais, mas de uma expectativa protegida por lei. Este é o componente de soberania detido pelo Congresso, que as partes não podem reter para si singularmente.

O que estava em jogo era uma situação típica do carona: se todos fossem obrigados a usar a nova moeda, desvalorizada, enquanto os detentores dos títulos indexados (especialmente os que haviam chegado à Suprema Corte), os custos da estabilização econômica e financeira seriam suportados por uma parte (os que não tinham títulos indexados), e os benefícios seriam distribuídos por todos: os detentores dos gold certificates estariam se beneficiando da nova situação sem ser atingidos pelos custos.

Os casos Wyatt, por seu turno, mostram a transformação do judiciário num administrador quando a proteção dos direitos sociais o envolve em pedidos, cuja implementação depende de políticas públicas. Em outras palavras, quando em vez de uma decisão exeqüível por simples transferência de uma coisa ou interesse de um indivíduo para outro, torna-se necessário apropriar-se de um fundo público, aplicá-lo e acompanhar sua aplicação, alterando inclusive o curso de aplicação/execução inicialmente adotado. Neste caso, o bem público tem o caráter definido por Olson, e o conflito é tipicamente policêntrico, como definido por Fuller. É público na medida em que um hospital ou um sistema hospitalar não é organizado para um único paciente, e, uma vez organizado, qualquer paciente qualificado na classe (pobre, indigente, submetido a medida de segurança, etc.) pode fazer uso dele. A provisão e o uso são naturalmente comuns: tanto que o pedido contido na ação era de fechamento do hospital e liberação dos internos, caso não fossem atendidos certos padrões de serviço, e não um tratamento específico para cada um dos autores em litisconsórcio. É policêntrico porque estão envolvidos interesses muito diferentes e opostos numa relação não-binária. O interesse do estado, por exemplo, não coincidia totalmente com o dos profissionais da saúde que administravam o hospital, que por sua vez não coincidia necessariamente com o dos internos, que por sua vez poderia chocar-se com o dos contribuintes carentes das cidades do interior, e assim por diante. Neste sentido, seria muito difícil alinhar apenas dois lados no conflito e seria também difícil decidir alocando o resultado numa soma zero. O fundo de onde deveriam sair os recursos para a reestruturação do sistema era o mesmo de onde sairiam todos os recursos do estado.

O resultado é que um juiz assim envolvido se transforma de julgador em administrador: pois não julga fatos passados de acordo com regras predefinidas, 
mas avalia atividades com critérios ainda não-definidos claramente. O julgador precisa nestas circunstâncias mais do que um instinto para o precedente. Ele não apenas ordena, precisa também fiscalizar e administrar. E depois de ordenar, pode ver-se diante da falta de dinheiro para cumprir sua ordem. Na falta de verbas para cumprir seu plano de reestruturação dos hospitais psiquiátricos do Alabama, o que poderia fazer o juiz Johnson? Reescrever o orçamento estadual? Ou se apropriar dos fundos públicos que julgasse conveniente, contrariando a previsão constitucional de que nenhum pagamento seria feito às expensas do Tesouro sem que houvesse previsão legal (Constituição dos EUA, art. I, sec. 9, 7). O passo final seria, naturalmente, que o juiz Johnson, na falta de verbas, lançasse também tributos gerais para conseguir cumprir sua decisão. Não apenas verbas, mas também recursos humanos seriam escassos: como conseguir suficientes médicos, enfermeiros e pessoal administrativo de uma hora para outra? Deslocando-os de outros hospitais obrigatoriamente, contrariando seja a vontade dos profissionais, seja a necessidade de outros serviços de saúde? Na época o Estado do Alabama dispunha de uma das mais baixas taxas de médico-pacientes nos EUA (Lieberman, 1981, p. 127). Impossibilitado de fazer isto, restava ao juiz Johnson transformar-se num mediador entre pacientes, hospitais e estado para implementar lentamente algumas melhoras factíveis. A série de casos representa, porém, um período de típico ativismo judicial, em que se colocava esperança no papel transformador e reformista dos tribunais (do judiciário).

O terceiro caso também apresenta questões tocando o conflito policêntrico. Há mais de um envolvido na disputa: há o Estado da Califórnia, mas dentro desta abstração existem os residentes ilegais. Estes, por sua vez, são nacionais de um Estado com o qual a União mantém relações políticas estreitas, inclusive submetidas a um sistema privilegiado (North American Free Trade AgreementNafta). Existem os interesses de a União promover algumas imigrações e desestimular outras. Existe uma limitação de recursos federais: Flórida, Texas, Nova Iorque são outros estados da União, nos quais a execução da Polícia de fronteiras é reclamada urgentemente, exigindo mais fundos e recursos. Existe a pressão de vários setores sociais e políticos para o corte dos recursos federais e diminuição do maior déficit público da história econômica mundial. O que priorizar? Trata-se da aplicação de uma regra a um caso ou da deliberação de como satisfazer simultaneamente interesses conflitantes e proporcionalmente legítimos? 
O argumento da Califórnia consistia em colocar a questão em termos de troca: a União é constitucionalmente responsável pelas fronteiras, pela política de imigração. A Califórnia vem tendo prejuízos, na medida em que se vê obrigada a prover alguns serviços públicos dos quais os imigrantes ilegais não podem ser excluídos e dos quais se beneficiam, onerando o estado. Que a União seja, portanto, condenada a pagar as despesas (em forma de reembolso ou indenização) e seja obrigada a proteger as fronteiras do estado de forma efetiva. De modo geral, os EUA alegam que a questão é política, não-justiciável, pois se trata de deliberar sobre os meios de conduzir uma atividade. De modo particular, fundamenta-se na legalidade de todos os atos da União e na inexistência de ilegalidade ou do dever de indenizar.

A decisão acata os argumentos dos EUA. Uma das razões fundamentais do acatamento está na impossibilidade de o tribunal determinar que o Departamento de Justiça e o procurador-geral exerçam suas funções administrativas de um certo modo apenas com relação ao Estado da Califórnia. São 51 estados sobre os quais a União deve exercer a guarda das fronteiras: a Flórida e o Texas, pelo menos, têm tantos problemas de imigração ilegal quanto a Califórnia, mas outros estados também apresentam suas dificuldades (Nova Iorque já foi a meca dos portoriquenhos e latinos, hoje recebe uma variedade de asiáticos, africanos e europeus orientais). Como pode o processo judicial, bipolar, particularizado e moldado para fazer retribuição, substituir o processo deliberativo da justiça distributiva? É esta a dificuldade fundamental, que impede a Corte Distrital de San Diego de avançar na condenação dos Estados Unidos frente à Califórnia. Caso aceitasse o pleito da Califórnia, o juízo seria obrigado a ordenar que todo o sistema de gastos fosse refeito, alocando diretamente os recursos que a sentença determinasse para a Califórnia e deixando os outros estados em potencial penúria. Este, sem dúvida, o obstáculo central, que impõe ao juízo federal de San Diego a atitude de deferência ao orçamento do Departamento de Defesa: nada de imoral ou escandaloso havia, senão uma decisão de alocar recursos escassos no nível nacional.

\section{Conclusão}

Todos os autores de obras relevantes em torno da teoria da justiça ou se apoiam numa concepção utilitarista ou são obrigados a argumentar contra o senso comum utilitarista. Assim, muito embora os autores hoje se filiem mais ou menos declaradamente a versões de éticas kantianas (como os libertários e os liberais), ou 
aristotélicas (como os comunitaristas), ambos vêem-se às voltas com uma justificativa de suas posições que permita dar suficiente importância ao tema da prosperidade nacional e individual. $\mathrm{O}$ apelo a direitos fundamentais em termos de sua validade absoluta (como na obra de Rawls e Dworkin) contrasta com o apelo a direitos fundamentais em termos de sua utilidade para o bem do indivíduo ou da república do utilitarista. Se a ética utilitarista é persistente, o seu critério de avaliação tende a ser o de uma análise custo-benefício.

Diferença considerável com relação ao debate desenvolvido no Brasil é que a discussão sobre a igualdade (econômico-social, quanto aos direitos sociais, e de respeito devido, quanto à não-discriminação) procede da vertente liberal de matriz kantiana. De uma ética individualista tem surgido um argumento a favor da igualdade por extensão, de respeito e reciprocidade. Os igualitaristas (liberais) transformaram o potencial indiferentismo individualista num ativo equal concern. No caso brasileiro, uma linha de justificação desta natureza ainda não surgiu, ou não se consolidou: em geral, o direito liberal (do estado de direito) e o direito social (do estado de bem-estar) são tidos como inconciliáveis num plano teórico. A própria Constituição de 1988 aparece para muitos como uma soma de perspectivas incompativeis e incompatibilizáveis racionalmente. E em geral a jurisprudência em certas jurisdições federais tende a interpretar o texto constitucional como uma proteção exclusiva da propriedade e da iniciativa privada.

Outro ponto a ressaltar é o grau de crítica norte-americano ao sistema judiciário e sua relação com a democracia. As críticas são de caráter institucional: procuram demonstrar a dificuldade de traduzir nos termos tradicionais de uma disputa judicial (bilateral, retributiva) as questões hoje relevantes de direitos sociais (plurilaterais, distributivos). Críticas são feitas ao caráter não-democrático do sistema judicial e seu papel de garantia do status quo em choque com o de defensor de direitos fundamentais. Shapiro (1988, p. 93) diz que "em muitos aspectos, um juiz federal de primeira instância é a coisa mais próxima de um ditador que nós toleramos em nosso sistema político. Para começar, ninguém os elegeu e eles tem o cargo vitalicio. Ao contrário das Cortes superiores, em que os juizes decidem em grupos de três ou mais e são pelo menos limitados uns pelos outros, o juiz de primeira instância decide sozinho. Nas suas varas são como pequenos deuses de lata que ninguém ousa contrariar. Outros analisam o comportamento das Cortes como resultado de pressões das opiniões dominantes. Ao mesmo tempo, é notável que a Suprema Corte e tribunais inferiores reconheça os limites de suas tarefas: costumam manter a presunção de constitucionalidade dos atos dos ramos eleitos do 
governo (em respeito à regra da maioria), propiciando a consolidação do regulatory state.

A não ser em casos de movimentos sociais fortes, também os tribunais norte-americanos tendem a confirmar a opinião social dominante. $\mathrm{O}$ mito de uma Suprema Corte independente é analisado na bibliografia político-constitucional por vários autores: só em casos mais recentes (como no do movimento pelos direitos civis), a Corte sentiu-se suficientemente forte (ou pressionada) para contrariar interesses tradicionais consolidados, fazendo valer o princípio da defesa das minorias (como regra essencial da democracia). Com o crescimento e a consolidação de uma onda conservadora, teme-se que a Corte não seja suficiente proteção para minorias ou para os que dependem de benefícios sociais.

No desenvolvimento brasileiro é claro que os tribunais serão chamados a decidir questões distributivas. Será preciso reconhecer se a natureza do conflito permite uma adjudicação tradicional e quais as instituições adequadas para processar tais demandas. Para novos problemas, novos remédios: ampliar o debate, de bilateral para plurilateral, aceitar acordos e negociar ordens, sem querer resolver tudo nas liminares, "sob pena de prisão dos administradores públicos", e dar-se conta de que a defesa da propriedade, como no caso da escravidão, nem sempre foi o non plus ultra da democracia e do direito. Em algumas jurisdições no Brasil é clara a influência da mainstream opinion, privatizante e estatofóbica. Vai chegar a hora de revê-la.

São Paulo, janeiro de 1997.

Bibliografia

CHAYES, Abraham. The role of the judge in public law litigation. Harvard Law Review (89), 1976.

DAWSON, John. The Gold Clause decisions. Michigan Law Review (33), 1935.

F. PAUL.(1988) Property Rights and Eminent Domain. New Brunswick/Oxford: Transaction Books.

FISS, Owen. The Forms of Justice. Harvard Law Review (93), 1976.

FULLER, Lon. The Principles of Social Order. Durham: Duke University, 1981.

GALBRAITH, John Kenneth. The Culture of Contentment. Boston/New York/London: Houghton Mifflin, 1992. 
GLAZER, Nathan. The Limits of Social Policy. Cambridge (Ma) / London: Harvard Univ. Press, 1988.

HIRSCH, Harry. A Theory of Liberty. New York/London: Routledge, 1992.

HORWITZ, J. The Transformation of American Law (1870/1960). New York/Oxford: Oxford Univ. Press, 1992.

JANSEN, Letácio. A Face legal do dinheiro. Rio de Janeiro: Renovar, 1991.

LIEBERMAN, Jethro. The Litigious Society. New York: Basic Books, 1981.

M. O'BRIEN. Constitutional Law and Politics. New York: W.W. Norton, 1995.

MENDES, Gilmar Ferreira, A Reforma monetária de 1990. Revista de Direito Administrativo. n. 186, 1991.

MERRYMAN, John. H.. The Civil Law Tradition. Stanford: Stanford University Press, 1990.

MICHELMAN, Frank. On Protecting the Poor through the Fourteenth Amendment. Harvard Law Review n. 83, 1969.

MOREIRA NETO, Diogo de Figueiredo. A Reforma monetária e a retenção dos ativos líquidos no Plano Brasil Novo. Revista de Informação Legislativa, n. 108, 1990.

NUSSBAUM, Arthur. Money in the law. Chicago, The Foundation Press, 1939.

Foundation Press, 1950.

Money in the law: national and international. Brooklyn: The

OLSON, Mancur. The Logic of Collective Action. Cambridge (Ma) London: Harvard Univ. Press, 1971.

REICH, Robert B.. (1983) The Next American Frontier. New York: Times Books.

ROSENBERG, Gerald, (1991) The Hollow Hope. Chicago/London: The University of Chicago Press.

SCHWARTZ, Bernard. (1990) The New Right and the Constitution.Boston: Northeastern Univ. Press

SHAPIRO, Martin. (1988) Who Guards the guardians? Judicial control of the administration. Athens/London: University of Georgia Press.

SHAPIRO, Martin. (1996) The 'globalization' of judicial review. L. Friedman \& H. Scheiber (ed) Legal Culture and the legal profession. Boulder (CO): Westview.

STEWART, Richard e C. Sunstein. (1982) Public Programs and Private Rights. Harvard Law Review, 95 (6)1194-1322. 
SUNSTEIN, Cass. (1993) The Partial Constitution. Cambridge (Ma)/London: Harvard Univ, Press. 